\title{
Dependence of maximal sniff generated mouth and transdiaphragmatic pressures on lung volume
}

\author{
T Wanke, G Schenz, H Zwick, W Popp, L Ritschka, M Flicker
}

\begin{abstract}
The maximal sniff generated mouth and transdiaphragmatic pressures of six healthy volunteers (three women and three men) were measured at various lung volumes between residual volume and $95 \%$ of total lung capacity. At residual volume the mean (SD) maximum transdiaphragmatic pressure was $163(18) \mathrm{cm} \mathrm{H}_{2} \mathrm{O}\left(1 \mathrm{~cm} \mathrm{H} \mathrm{H}_{2} \mathrm{O}=0.0981 \mathrm{kPa}\right)$. With increasing lung volume the maximum pressures generated declined, so that at $95 \%$ of total lung capacity the mean pressure was 68 (15) $\mathrm{cm} \mathrm{H}_{2} \mathrm{O}$. Mouth pressures showed a similar relation to lung volume. At residual volume the mean maximum mouth pressure was $74(8) \mathrm{cm} \mathrm{H} \mathrm{H}_{2} \mathrm{O}$, compared with $38(6) \mathrm{cm}$ $\mathrm{H}_{2} \mathrm{O}$ at $95 \%$ of total lung capacity. The relation between pressure and lung volume was linear for measurements at lung volume levels between residual volume and $85 \%$ of total lung capacity; values at $95 \%$ of total lung capacity, however, were lower than predicted from the linear regression of the other points. The use of a second order polynomial regression showed a higher coefficient of determination in all cases $(0.72$ and 0.69 for transdiaphragmatic and mouth pressures on the basis of all pressure values for all subjects). Sniff generated mouth and transdiaphragmatic pressures show a predictable dependence on lung volume, supporting their use as measures of global inspiratory muscle power and diaphragm strength respectively.
\end{abstract}

Measurement of inspiratory muscle strength provides the clinician with valuable information about the origin of respiratory failure. ${ }^{12}$ The maximal inspiratory pressure generated at the mouth against a closed shutter is a measure of global inspiratory muscle strength..$^{3-7}$ The test requires a mouthpiece, and some patients with neuromuscular disease are unable to use this. The diaphragm is the major inspiratory muscle, and its strength can be analysed separately. Transdiaphragmatic pressure is believed to be the most accurate measure of the strength of diaphragm contraction. ${ }^{89}$ It has usually been measured during a slow full inspiration or during maximal static inspiratory efforts against a closed shutter at various lung volumes. ${ }^{8-12}$ Because of the large variation between individuals in the pattern of pressure generation during these two types of respiratory manoeuvres, transdiaphragmatic pressure values are easily misinterpreted. ${ }^{13}$

A new method for assessing diaphragm strength is to measure transdiaphragmatic pressure during a maximal sniff manoeuvre. ${ }^{14}$ A new index of global inspiratory muscle strength has also been introduced: the pressure within the mouth during a maximal sniff manoeuvre. ${ }^{15}$ This method has the advantage that a mouthpiece is not necessary.

Until now transdiaphragmatic and mouth pressures measured during maximal sniff manoeuvres have been analysed only at two levels of lung volume: at residual volume (RV) and at resting end expiration. ${ }^{14} 15$ This study was designed to evaluate the influence of intrathoracic gas volume (expressed as a percentage of total lung capacity) on the maximal sniff generated mouth and transdiaphragmatic pressures. We also analysed the interindividual and intraindividual variation of mouth and transdiaphragmatic pressure values at different lung volumes between RV and total lung capacity (TLC).

\section{Methods}

PRESSURE MEASUREMENTS

We measured transdiaphragmatic pressure (Pdi) with a flexible double lumen catheter (internal diameter of each lumen $1.4 \mathrm{~mm}$ ). The catheter was positioned with the distal lumen slightly below the cardia $(65-70 \mathrm{~cm}$ from the nares) and the proximal lumen in the middle third of the oesophagus $(35-40 \mathrm{~cm}$ from the nares). At the distal end of both lumina two lateral foramina (diameter $1.8 \mathrm{~mm}$ ) provided free communication with the surroundings. The catheter was perfused with distilled water at a constant flow of $25 \mathrm{ml} /$ hour. The proximal ends were coupled to a pressure transducer (Gould-Statham, typ P23ID). Pressure was displayed on a four channel paper recorder (Beckman 511A), which showed a 50\% reduction of the selected maximal amplitude at $45 \mathrm{~Hz}$. Transdiaphragmatic pressure was calculated by subtracting oesophageal pressure from gastric pressure. Both gastric and oesophageal pressure were arbitrarily equated with zero at the start of each sniff trial. Thus only the change in pressure from the initial position was determined for each sniff.

Mouth pressure $(\mathrm{Pm})$ was measured with a flexible single lumen catheter (internal diameter $1.8 \mathrm{~mm}$ ) with two lateral foramina (diameter $1.8 \mathrm{~mm}$ ) at the distal end. This catheter was also perfused with distilled water at a constant flow of $25 \mathrm{ml} /$ hour. Mouth pres-
Address for reprint requests: Department, Hospital Lainz, Wolkersbergenstrasse 1, Accepted 29 January 1990 
sure was transmitted and displayed in the same manner as transdiaphragmatic pressure. The mouth pressure from which the sniff was started was again set arbitrarily at zero.

SUBJECTS AND PROTOCOL

Studies were carried out on six subjects, three women and three men, aged 24-30 (mean 27.7) years. The subjects had no respiratory symptoms or neuromuscular disease and had normal lung function.

Lung volume was determined in a constant volume whole body plethysmograph (Jaeger, Würzburg) on five successive days to measure intraindividual variation of FRC (maximal and minimal values did not differ by more than 0.4 litres). The sniff measurements were made on five additional successive days, to check the reproducibility of the data, with the subject in a sitting position.

The catheter for measurement of oesophageal and gastric pressure was inserted via the nose after local anaesthesia had been given. The mouth catheter was positioned as close as possible to the posterior wall of the pharynx. Sniffs were initially carried out at resting end expiration (FRC). The volunteers were asked to sniff quickly, and as hard as possible, through the nose with the mouth closed. A nose clip was not used. An interval of 30-45 seconds was allowed beteen each sniff. Data were collected only after a plateau value of peak sniff pressures was reached (usually within five sniffs). At that point the volunteer was required to sniff 10 more times to ensure that there was no further increase, and the five highest mouth and transdiaphragmatic pressure values were selected for analysis. A further series of sniffs was then carried out after maximal expiration (RV). To ensure a constant maximal expiration, breathing was registered on a bell spirometer connected to a well fitting mask with preformed holes for the catheters, and the subject watched the curve on the spirometer. Ten sniff manoeuvres were performed at RV, with 30-45 second intervals between each attempt. The five highest values were again selected. Finally, the subject was required to inhale maximally and then exhale to a predetermined lung volume (as a percentage of TLC) followed by a maximal sniff. The predetermined lung volumes were marked on the spirometer. The first volume was $68 \%$, the second $85 \%$, and the third $95 \%$ TLC. At each volume the best five of 10 sniffs were again selected for analysis.

\section{STATISTICAL METHODS}

The relation between lung volume and the pressure measurements was assessed by five forms of regression in each subject-namely, linear, exponential, logarithmic, power law, and least squares best fit polynomial regression of the second order. Although the data were not strictly homoscedastic, coefficients of determination $\left(R^{2}\right)$ and $p$ values were used to assess each regression, to give a guide to the fit of these approximations. The difference between the coefficients of determination for the linear regression and for the second order polynomial regression was determined separately (by calculating $F$ values). For each person 125 pressure values were available (five measurements at five lung volumes on five days).

The regressions were also applied to the pressure measurements for the three women separately ( 375 values for each group) and for all six subjects together ( 750 values).

Variation within subjects on the same day was calculated as the difference between the highest and the lowest pressure value at each lung volume (five measures a day). The variation within subjects between days was expressed as the coefficient of variation $(100 \times$ $\mathrm{SD} /$ mean) for the 25 pressure measurements at each lung volume. The distribution of these 25 data points (for the six subjects 30 distributions altogether) differed significantly $(p<0 \cdot 1)$ from a normal distribution in only two cases (Pearson-Stephens-Test). Intersubject variation at each lung volume was assessed from the coefficient of variation for men and women separately and for all six subjects (coefficient of variation based on 150 measurements).

For each subject the data taken over five days were examined for a possible training effect (increase in pressure with time) at each lung volume by means of linear regressions. The $t$ test was used to check whether the slopes obtained (b values) showed any significant deviation from zero.

\section{Results}

The sniff manoeuvres were performed by all volunteers without difficulty. During the sniff a rapid negative pressure peak was observed in the mouth and oesophagus and a positive pressure peak in the stomach. The contribution of oesophageal (Poe) and gastric $(\mathrm{Pg})$ pressure to sniff Pdi varied between subjects, though none had a negative $\mathrm{Pg}$ at peak Pdi. For maximum sniff mouth pressures and transdiaphragmatic pressures the highest values were achieved at $\mathrm{RV}$ (mean (SD) value in $\mathrm{cm} \mathrm{H}_{2} \mathrm{O}^{\star}$ for Pdi 163 (18), Pm 74 (8)) and the lowest values at $95^{\circ}$. TLC (Pdi 68 (15), Pm 38 (6); tables 1 and 2, figs 1 and 2).

Linear and second order polynomial regression fitted the data points better than logarithmic, exponential, or power law functions. This

${ }^{\star} 1 \mathrm{~cm} \mathrm{H} \mathrm{H}_{2} \mathrm{O}=0.0981 \mathrm{kPa}$

Table 1 Mean values with ranges for sniff generated mouth pressures for the six subjects at each lung volume. *

\begin{tabular}{llll}
\hline \multicolumn{4}{c}{ Mouth pressure (mean (range)) } \\
\cline { 2 - 4 } Lung volume & $\mathrm{cm} \mathrm{H}_{2} \mathrm{O}$ & $S D$ & $\mathrm{CV}(\%)$ \\
\hline${ }^{\circ} \mathrm{TLC}$ & & & \\
95 & $38 \cdot 3(23-55)$ & $6 \cdot 9(4 \cdot 7-5 \cdot 6)$ & $18 \cdot 2(11 \cdot 1-14 \cdot 1)$ \\
85 & $49 \cdot 7(34-69)$ & $7 \cdot 2(4 \cdot 9-7 \cdot 8)$ & $14 \cdot 5(11 \cdot 0-15 \cdot 6)$ \\
68 & $60 \cdot 2(45-78)$ & $7 \cdot 6(5 \cdot 6-6 \cdot 6)$ & $12 \cdot 7(8 \cdot 9-11 \cdot 6)$ \\
FRC & $65 \cdot 2(44-89)$ & $7 \cdot 9(4 \cdot 7-6 \cdot 3)$ & $12 \cdot 1(7 \cdot 7-10 \cdot 4)$ \\
RV & $74 \cdot 5(58-92)$ & $8 \cdot 2(4 \cdot 4-6 \cdot 0)$ & $10 \cdot 9(6 \cdot 5-8 \cdot 7)$ \\
\hline
\end{tabular}

TLC - total lung capacity; FRC-functional residual capacity; RV-residual volume.

* Standardised deviations (SD) and coefficients of variation $(\mathrm{CV})$ were derived from $150(6 \times 25)$ pressure values at each lung volume. The range of $\mathrm{CV}$ and SD derived from the 25 pressure values for each person is given in parentheses. Conversion: Traditional to SI units $-1 \mathrm{~cm} \mathrm{H} \mathrm{H}_{2} \mathrm{O}=0.0981 \mathrm{kPa}$. 
Table 2 Mean values with ranges for sniff generated transdiaphragmatic pressures for the six subjects at each lung volume*

\begin{tabular}{|c|c|c|c|}
\hline \multirow{2}{*}{$\begin{array}{l}\text { Lung } \\
\text { volume }\end{array}$} & \multicolumn{3}{|c|}{ Transdiaphragmatic pressure (mean (range), $\mathrm{cm}_{2} \mathrm{O}$ ) } \\
\hline & Mean & $S D$ & $C V(\%)$ \\
\hline \\
\hline & $\begin{array}{l}6-108) \\
1-130)\end{array}$ & $\begin{array}{l}15 \cdot 3(7 \cdot 8-11 \cdot 6) \\
17 \cdot 0(10 \cdot 4-11 \cdot 4)\end{array}$ & $\begin{array}{l}5-16 \cdot 5) \\
2-13 \cdot 2)\end{array}$ \\
\hline & 122 & 17.2( & 14.0 \\
\hline RC & 137.8( & 17.8 & $-9 \cdot 5)$ \\
\hline & $163.5(128-202)$ & $18 \cdot 0(11 \cdot 1-11 \cdot 4)$ & $11 \cdot 0(6 \cdot 8-7 \cdot 7)$ \\
\hline
\end{tabular}

*Standard deviations (SD) and coefficients of variation (CV) were derived from $150(6 \times 25)$ pressure values at each lung volume. The range of $C V$ and SD derived from the 25 pressure values for each person is given in brackets.

Abbreviations as in table 1 .

Conversion: Traditional to SI units $-1 \mathrm{~cm} \mathrm{H}_{2} \mathrm{O}=0.0981 \mathrm{kPa}$.

Figure 1 Individual curves for maximal sniff generated mouth (Pm) pressures as parabolic functions of lung volume (o total lung capacity (TLC)).

$P\left(\mathrm{~cm} \mathrm{H} \mathrm{H}_{2} \mathrm{O}\right)$

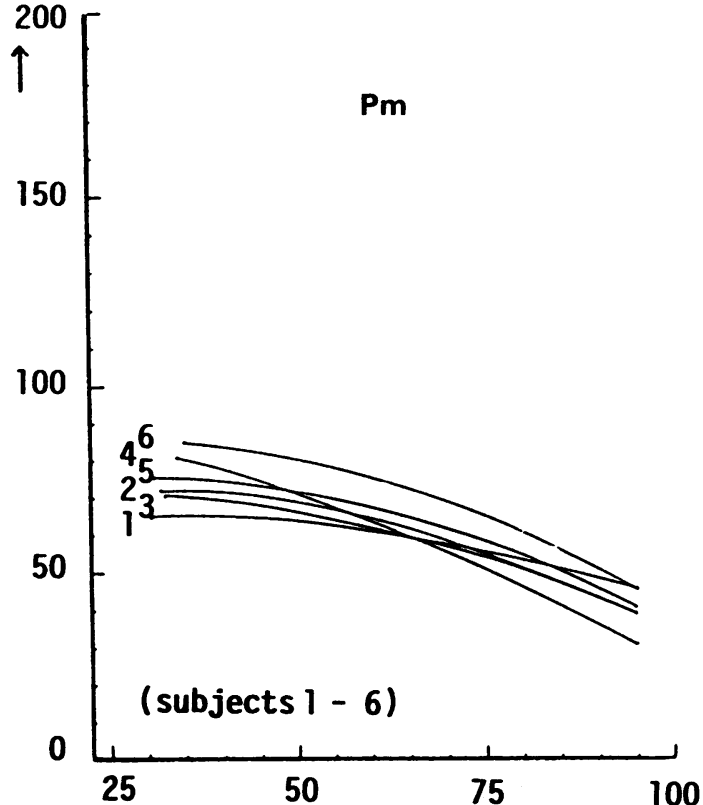

$\rightarrow V(\%$ TLC $)$

Figure 2 Individual curves for maximal sniff generated transdiaphragmatic (Pdi) pressures as parabolic functions of lung volume (\% total lung capacity (TLC)). Subjects 1-3 female; subject 4-6 male.

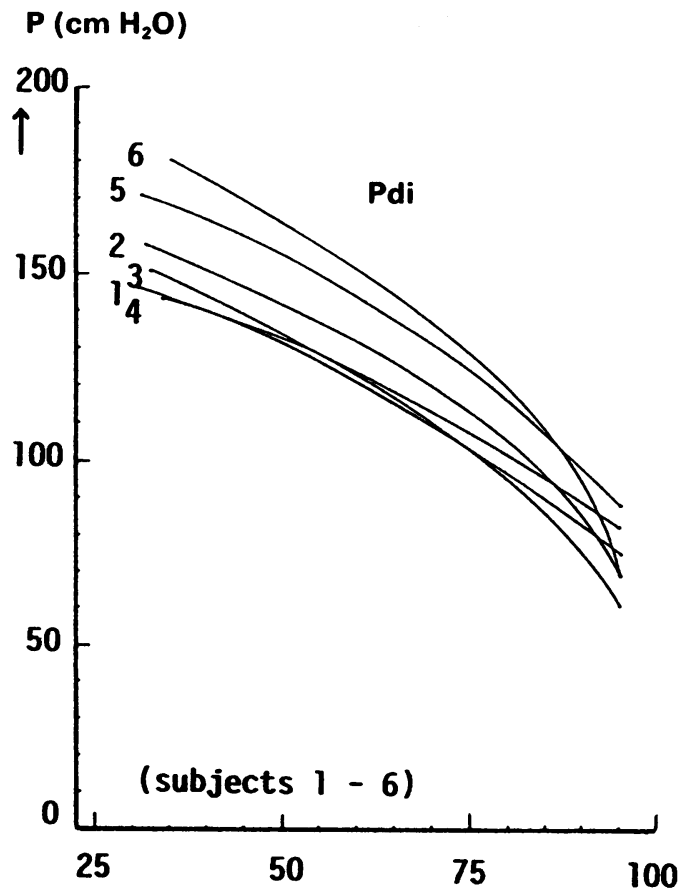

$\rightarrow \mathrm{V}(\% \mathrm{TLC})$ was true for the data for each subject ( $n=125$ pressure values), for the data for women ( $\mathbf{n}=375$ ) and men ( $\mathbf{n}=375$, and for all subjects together $(n=750)$. The differences between the coefficients of determination of linear and second order polynomial regressions and those of all other forms of regression were significant in occasional cases only at $p<0.01$ ( $z$ transformation, $t$ test). The coefficients of determination for the second order polynomial regressions for individual subjects (range $\mathbf{0 . 7 4}$ 0.92 for Pdi, 0.69-0.90 for Pm) exceeded in all cases those for linear regressions (range $\mathbf{0 . 6 7 -}$ 0.90 for Pdi, $0.66-0.88$ for Pmo). Findings were similar for the three men and the three women and for all six subjects. The $p$ value for the coefficients of determination for both the linear and the second order polynomial regressions was $<0.001$. The improvement of the linear regression by a square component was not significant in any case ( $F$ test). Lower coefficients of determination were obtained for all five regressions when men and women were analysed together rather than separately (tables 3 and 4).

The maximum variation within subjects on the same day was $9 \mathrm{~cm} \mathrm{H}_{2} \mathrm{O}$ for Pmo and $30 \mathrm{~cm}$ $\mathrm{H}_{2} \mathrm{O}$ for Pdi. The within subject between days coefficient of variation ( $\%$ ) for the six ranged from 6.5 to 15.6 (mean 10.8 ) for sniff $\mathrm{Pm}$ and from 6.8 to 16.5 (mean 11.2) for Pdi.

The coefficient of variation $(\%)$ between subjects for sniff $\mathrm{Pm}$ ranged from 7.8 to $16 \cdot 1$ (mean $15 \cdot 1$ ) in the women, from $7 \cdot 2$ to 15.3 (mean 14.5) in the men, and from 10.9 to 18.2 (mean 15.2) in all six subjects. The coefficient of variation between subjects for sniff Pdi ranged from 6.7 to 20.6 (mean 13.0) in the women, from 8.3 to 22.8 (mean 13.5 ) in the men, and from 11.0 to 22.4 (mean 17.3 ) in all six subjects. The coefficients of variation calculated from the 150 measurements for all subjects at each lung volume depended mainly on differences in pressure values between subjects and less on the variability of pressure values within subjects.

Only one of the 30 sets of data showed a significant $(p<0.025)$ increase in pressures with time (a training effect).

\section{Discussion}

In this study we used catheters perfused at a constant flow with distilled water instead of balloon catheters containing air. The two systems show little difference in the speed of pressure transmission. ${ }^{16}$ We think, however, that the perfused catheters are easier to work with.

De Troyer et al ${ }^{13}$ showed high intersubject variability in transdiaphragmatic pressure values obtained during slow maximal inspiration and maximal static inspiratory contraction against a closed shutter. They were unable to obtain normal values or assess the relation between the pressures they obtained and intrathoracic gas volume.

Miller and Moxham $^{14}$ were the first to measure transdiaphragmatic pressure during a maximal sniff. They found that the pressures 
Table 3 Regression equations for lung volume, expressed as percentage of total lung capacity (TLC), as a parabolic function of mouth pressure (Pm) in female and male subjects and the two combined

\begin{tabular}{lllll}
\hline Sex & Equations & $R^{2}$ & $p$ & $n$ \\
\hline Female & o TLC $=47.04+3.04 \mathrm{Pm}-0.047 \mathrm{Pm}^{2}$ & 0.76 & $<0.001$ & 3 \\
Male & o TLC $=109.7+0.017 \mathrm{Pm}+0.011 \mathrm{Pm}^{2}$ & 0.72 & $<0.001$ & 3 \\
All subjects & o TLC $=145.6-1.26 \mathrm{Pm}-0.0014 \mathrm{Pm}^{2}$ & 0.69 & $<0.001$ & 6 \\
\hline
\end{tabular}

Table 4 Regression equations for lung volume, expressed as percentage of total lung capacity (TLC), as a parabolic function of transdiaphragmatic pressure (Pdi) in female and male subjects and the two combined

\begin{tabular}{lllll}
\hline Sex & Equations & $R^{2}$ & $p$ & $n$ \\
\hline Female & o TLC $=92.07+0.35 \mathrm{Pdi}-0.005 \mathrm{Pdi}^{2}$ & 0.78 & $<0.001$ & 3 \\
Male & o TLC $=98.8+0.13 \mathrm{Pdi}-0.0027 \mathrm{Pdi}^{2}$ & 0.75 & $<0.001$ & 3 \\
All subjects & o ${ }^{2}$ TLC $=122.8-0.35 \mathrm{Pdi}-0.00087 \mathrm{Pdi}^{2}$ & 0.72 & $<0.001$ & 6 \\
\hline
\end{tabular}

showed little variability between or within normal subjects. We found little variability within and between subjects at other lung volumes. This was true for both maximum sniff mouth pressures and transdiaphragmatic pressures.

Mouth pressure at RV during a maximal sniff was lower than the pressures recorded by other authors during a maximal static inspiratory effort against a closed shutter. ${ }^{467}$ This difference could be due to the so called "mouthpiece effect." Rochester et al ${ }^{17}$ showed that by the use of a mouthpiece the electrical activity of the diaphragm rose significantly in both healthy volunteers and patients during quiet breathing. This increase in electrical activity was not suppressed during ventilation by a tank respirator. Possibly when a mouthpiece is used the inspiratory muscles are stimulated and produce higher pressure values. Koulouris et $a l^{18}$ found that the height of the measured mouth pressure values also depended on the design of the mouthpiece used.

The relation of maximal static pressures generated by the respiratory system may be linear ${ }^{319}$ or parabolic. ${ }^{4}$ Our results suggest that the curve is parabolic and flattened near to total lung capacity. The force developed is influenced by the length-tension curve of the respiratory muscles, which is parabolic. ${ }^{20}$ Muscle fibres produce substantially less force at shorter or longer lengths than at optimal length. Gordon $e$ al $^{21}$ in in vitro experiments on single fibres from amphibian muscles showed that the length-tension curve for the segment $L / L_{0}$ between 0.5 and $1.0(\mathrm{~L}=$ actual muscle fibre length $\mathrm{L}_{0}=$ optimal muscle fibre length) has two ranges in which the tension increases linearly, connected by an inflection point. The second order polynomial regression, yielding a curve that is linear over a wide range, may reflect this phenomenon.

Sniff generated mouth and transdiaphragmatic pressure values have a low interindividual and intraindividual variability and a predictable dependence on lung volume. The mouth pressures appear to provide a satisfactory estimate of global inspiratory muscle power and the transdiaphragmatic pressures of the strength of the diaphragm.

We thank Mrs Neudecker for skilled technical assistance, and Mrs Weber for translating the manuscript.

1 Roussos Ch, Macklem PT, The respiratory muscles. $N$ Engl J Med 1982;23:786-97.

2 Sigrist $S$, Thomas D, Howell S, Roussos Ch. The effect of aminophylline of inspiratory muscle contractility. Am Rev Respir Dis 1982;126:46-50

3 Cook CD, Mead J, Orzalesi MM. Static volume-pressure characteristics of the respiratory system during maximum efforts. J Apply Physiol 1964;19:1016-21.

4 Rinqvist $T$. The ventilatory capacity in healthy subiects: an analysis of causal factors with special reference to the respiratory forces. Scand J Clin Lab Invest 1966;18(suppl
88):170.

5 Byrd RB, Hyatt RE. Maximal respiratory pressures in chronic obstructive lung disease. Am Rev Respir Dis 1968;98:848-56.

6 Black LF, Hyatt RE. Maximal respiratory pressures; normal values and relationship to age and sex. Am Rev Respir Dis values and relationshi

7 Wilson SH, Cooke NT, Edwards RHT, Spiro SG. Predicted normal values for maximal respiratory pressures in caucasian adults and children. Thorax 1984;39:535-8

8 Loh L, Goldman M, Newsom Davis J. The assessment of diaphragm function. Medicine (Balitmore) 1977;56: 165-9.

9 Newsom Davis J, Goldman M, Loh L, Cosson M. Diaphragm function and alveolar hypoventilation. $Q J$ Med 1976;45:87-100.

10 Gibson GJ, Pride NB, Newsom Davis J, Loh LC. Pulmonary mechanics in patients with respiratory muscle weakness. Am Rev Respir Dis 1977;115:389-95.

11 Kreitzer SM, Saunders NA, Tyler HR, Ingram RM Jr. Respiratory muscle function in amyatrophic lateral Respiratory muscle function in amyatroph

12 Gibson GJ, Edmonds JP, Hughes GRV. Diaphragm function and lung involvement in systemic lupus erythematosus. Am J Med 1977;63:926-32.

13 De Troyer A, Estenne M. Limitations of measurement of transdiaphragmatic pressure in detecting diaphragmatic weakness. Thorax 1981;36:169-74.

14 Miller JM, Moxham J, Green M. The maximal sniff in the assessment of diaphragm function in man. Clin $\mathrm{Sci}$ 1985;69:91-6.

15 Koulouris N, Sawicka EH, Vianna LG, Barnes N, Green M, Moxham J. Sniff mouth pressures reflect inspiratory muscle strength [ABSTRACT]. Clin Sci 1987;72:86.

16 Kinnear W, Knowles K, Rocker G. Comparison of balloon and perfusion systems in the measurement of transand perfusion systems in the measurement

17 Rochester DF, Braun NMT, Loine S. Diaphragmatic energy expenditure in chronic respiratory failure. $\mathrm{Am} \mathrm{J}$ Med 1977;63:223-32

18 Koulouris N, Mulvey DA, Laroche CM, Green M, Moxham J. Comparison of two different mouthpieces for the measurement of $P_{i} \max$ and $P_{t} \max$ in normal and weak subjects. Eur Respir J 1988;1:863-7.

19 Rahn H, Otis AB, Chadwick LE, Fenn WO. The pressurevolume diagram of the thorax and lung. Am J Physiol 1946;146:161-78.

20 Edwards RHT, Faulkner JA. Structure and function of the respiratory muscles. In: Roussos Ch, Macklem PT, eds. The thorax. Part A. New York: Dekker 1985:297-326.

21 Gordon AM, Huxley AF, Julian FJ. The variation in isometric tension with sarcomere length in vertebrate muscle fibers. J Physiol 1966;184:170-92. 